\title{
"My First Humanoid Robot" An Experience worth Sharing with Freshmen and Sophomore
}

\author{
Bikram Adhikari \\ Department of Electronics and Computer Engineering, Pulchowk Campus, Institute of Engineering, \\ Tribhuvan University, Nepal \\ Corresponding email: bikram.adhikari@ioe.edu.np
}

\begin{abstract}
As the world around is becoming overwhelmed with sophisticated embedded gadgets and robots, it is indispensable to create enthusiasm among students about embedded systems and robotics in their early career. While embedded platforms are an attractive option to learn and implement new technologies, most freshmen and sophomore engineering students have not acquired sufficient skills to understand and use the complex development tools needed to program these platforms. Students need simpler and spontaneous environment to experiment with their creativity and apply basic engineering concepts. Sharing an experience of building a humanoid robot with LEGO Mindstorms NXT ${ }^{\circledR}$, this paper presents the LEGO Mindstorms Kit as a useful tool for freshman and sophomore students to learn robotics and embedded systems.
\end{abstract}

Key Terms- LEGO Mindstorms, Robotics, Embedded Systems

\section{Introduction}

The world around us is exploring new horizons of technology at an ever-accelerating pace, especially in embedded systems, computers and automation. While embedded platforms are an attractive option to learn and implement new technologies, most freshmen and sophomore engineering students have not acquired sufficient skills to understand and use the complex development tools needed to program these platforms. There has been an increasing number of ill-prepared students enrolled in engineering courses, who neither have the required pre-requisites from their intermediate level school courses, nor do they know much about their field of interest [1].

To ensure that we produce qualified engineers, not only theoretically but in practical applications as well, activity based technology curriculum is needed at the school level, as well as early engineering courses, to give students an insight into engineering fields and attract students to technology studies [2]. As opposed to the traditional education approach, technology curriculum should be more practice oriented and activity based. Therefore, new approaches are needed to design and implement high quality technology programs at beginning of engineering education.

Robotics, being a multifaceted representation of modern science and technology, fits into this planning perfectly. Robotics is defined as an intelligent connection between perception and action [3]. It is an engineering art combing electrical and mechanical technologies. It is widely used nowadays and is part of our daily life. In the industrial area, robots are widely use to increase productivity and hence production capacity. 
It is an excellent way to introduce students to integrated areas of science, technology, engineering and mathematics (STEM) [1]. However, due to the complexity of robotics studies, it is hard to attract and pass the knowledge to students [2].

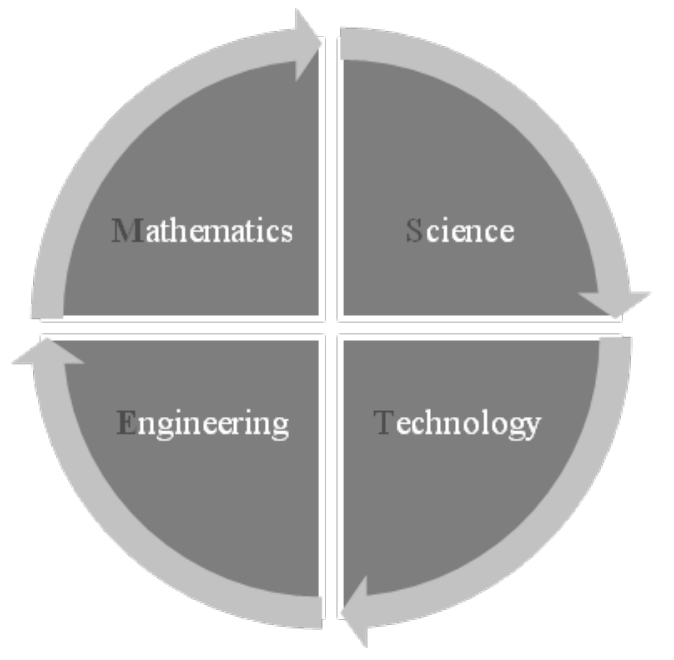

Figure 1: Integrated STEM areas

This paper, presents the comparative analysis of LEGO Mindstorms NXT with traditional learning approach and its capabilities to be an interactive platform for school students as well as freshman and sophomore engineering students to learn embedded systems and robotics using simple mechanical parts and graphical software.

\section{LEGO Mindstorms}

The Lego Mindstorms Kit is a set of robotics for the educational area, which lets you create and program robots, using simple mechanical parts, in order to perform simple and complex tasks. The kit consists of mounting blocks, motors, sensors, and a microprocessor as the brain of the system [4].

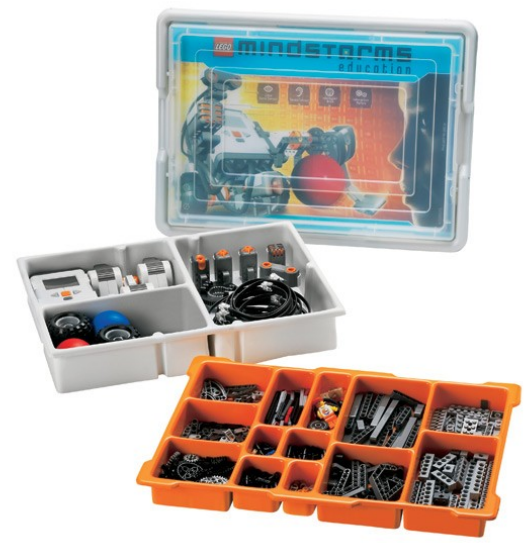

Figure 2: LEGO Mindstorms Education Base Set [4] 


\section{LEGO NXT Brick}

Figure 3 shows the block diagram of LEGO Mindstorms NXT "brick". Its central processor is a 32-bit Atmel ARM7 processor with 256KB Flash and 64KB RAM operating at $48 \mathrm{MHz}$. It has a $100 \times 64$ pixel LCD graphical display and an 8-bit resolution sound channel. The brick can be programmed with Bluetooth radio and can store multiple programs which can be selected using buttons [4].

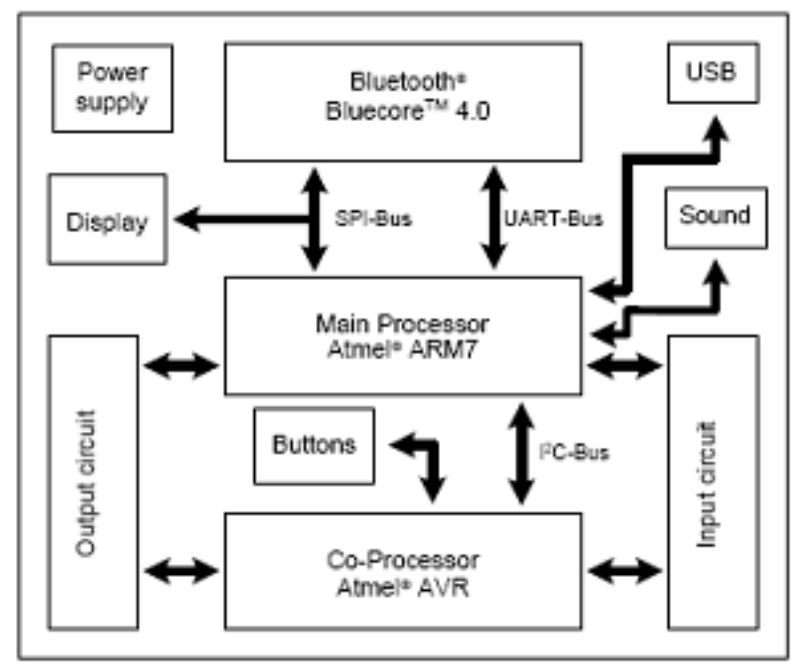

Figure 3. Block Diagram of LEGO Mindstorms NXT Brick [5]

From a freshmen or sophomore student point of view, to program such a system by conventional techniques would require a knowledge challenging tool chain. Another consideration is that this "toy", as stated by LEGO, is suitable for kids from ages 8 and above. With these contradictions, LEGO introduces a different approach to programming these systems which focuses more on the concept implementation and less on bit-level operations.

\section{LEGO Mindstorms NXT Software}

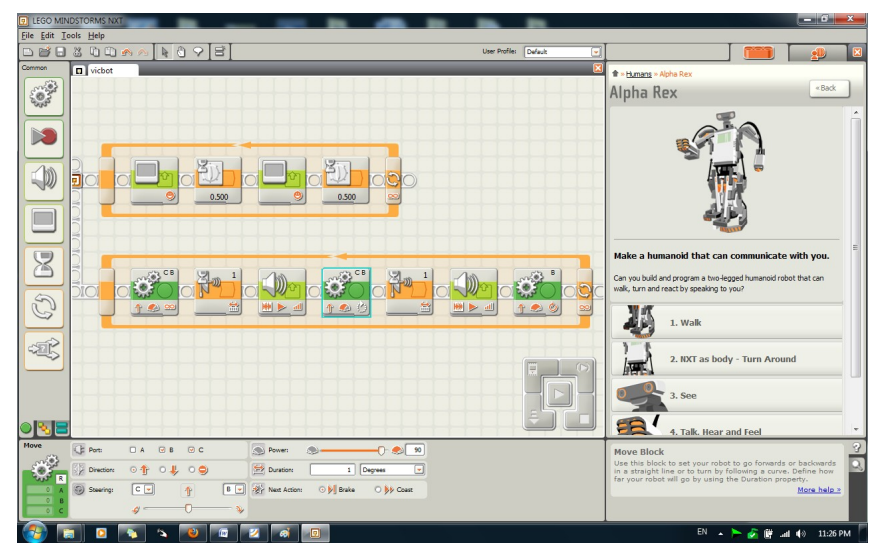

Figure 4. LEGO Mindstorms NXT Software [4] 
As mentioned in the previous section, programming the NXT brick by 8 year-olds and subsequently freshman and sophomore engineering students needs a noble approach primarily because of the limited skill sets of the students. The LEGO Mindstorms NXT kit provides a wonderful software development platform that can be used to program the brick without having any prior knowledge of programming. Figure 4 shows an example of a program that is written in this Mindstorms NXT software [6].

Since the program is completely graphical, it helps students focus more on the design aspect rather than starting with the basic but complicated phase of learning new tools and associated abstract syntaxes. Another important feature of graphical programming is the concept of parallel programming, which is inherently hard to teach with a traditional approach. The parameters associated with a block can be easily configured at the bottom of the screen itself. This software also exposes some key embedded concepts such as memory and resource management in a fun environment.

\section{LEGO Sensors and Motors}

Figure 5 shows a range of sensors and motors. LEGO Mindstorms NXT 2.0 comes with two touch sensors, one ultrasonic sensor for measurement of distance ranging from $5 \mathrm{~cm}$ to $250 \mathrm{~cm}$, one microphone and one color sensor that can identify fifteen different colors. These sensors can be easily calibrated using a simple program within the software [4].

There are three DC motors with a built-in tachometer feedback to provide robust position and velocity response.

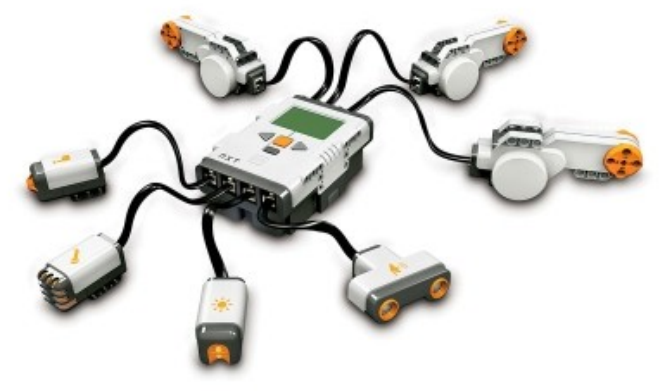

Figure 5: LEGO Mindstorms NXT Sensors and Motors [4]

\section{LEGO Building Blocks}

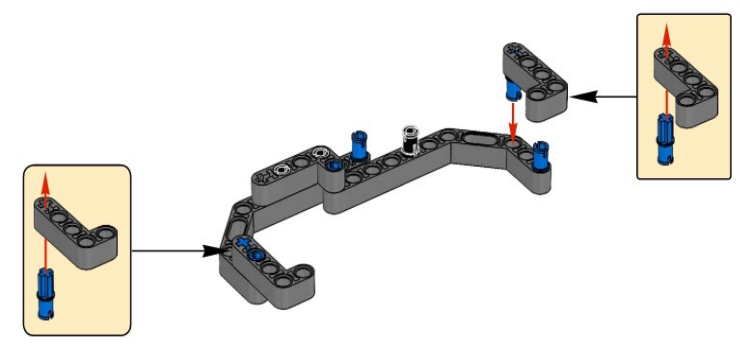

Figure 6. LEGO Mindstorms Building Instruction 
Using a traditional learning approach, students find it ominously challenging and daunting to build all the basic parts of a robot from scratch. Freshmen and sophomores find it very difficult and costly to learn with the traditional approach. With LEGO Mindstorms, the physical structure of the robot and other mechanical framework can be built with LEGO building blocks without the requirement of costly and sophisticated workshops and tedious labor. There are various LEGO building instructions to assemble a range of robots on the official LEGO website [4]. Figure 4 shows the building instructions for a part of a LEGO humanoid robot's leg.

\section{My first LEGO Humanoid Robot}

Making a robot is not an easy task. The knowledge of robotics and automation is not acquired by turning the pages of lecture notes and submitting weekly assignments. Making a complete, fully operational system takes a lot of effort, knowledge and perseverance. In addition, the challenge is further complicated by the unavailability of equipment that necessitates development from scratch. For beginners, robotics is an incredibly daunting field to get into.

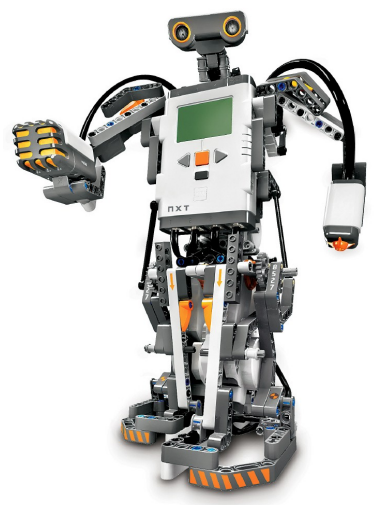

Figure 7 Mindstorms NXT Humanoid Robot

Recently, I built a humanoid robot, my childhood dream, using LEGO Mindstorms NXT. With my nerve wrecking prior experiences of creating simple yet complicated to build robots, I was astounded to see myself building a humanoid robot effortlessly. Following the building instructions and using a drag and drop programming environment was just so simple. Finally the robot walked up to me and said, "Hello!!!" It was a wonderful experience.

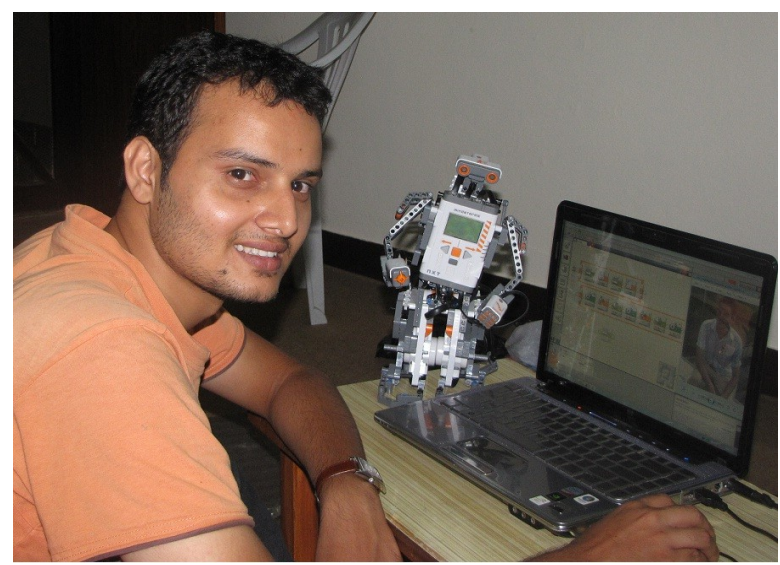

Figure 8. LEGO Humanoid Robot Experience 
In the mean time, I had a flash back into my past robotic experiences. I don't remember making a robot without using a multimeter or soldering iron, or going through lumps of datasheets, or pondering in front of an oscilloscope wondering, "Why is there a $500 \mathrm{mV}$ spike in the signal?" More than $80 \%$ of the time was spent on development of fundamental parts of the robot. A major portion of mechanical job was to work for hours and hours with a lathe machine to make shafts, bushings and wheels. As a beginner in robotics, I spent hours and hours going through datasheets and surfing the internet to discover some basic principles and techniques. When I was making this humanoid robot, I laughed at my silly mistakes in the past and realized how easy and effective would it had been if I had an opportunity to use this kit as a sophomore. I don't say that all that I went through was useless. It is important to have a strong foundation, be able to accomplish every single piece of work oneself and acquire in-depth knowledge of engineering. However, LEGO Mindstorms can be the right point to start from.

LEGO Mindstorms can turn out to be an exceptional platform for a variety of research purposes. Especially designed for students from age 8 years and above this unique platform integrates the key traits of activity based learning. Not only for educational robotics, this extremely powerful platform can be used as a base platform to start learning programming and embedded systems. To understand and implement various mechanisms without having to go to a workshop may lead mechanical students to use this kit as well.

\section{Conclusion}

In this paper, LEGO Mindstorms NXT has been presented as an indispensable tool to introduce embedded systems and robotics to school students and freshmen and sophomore engineering students.

Many students find early courses in engineering to be abstract and often narrowly focused with rigorous mathematics. Platforms like LEGO Mindstorms are compact, cost effective and simple packages that provide flexibility in design and development of robots and other embedded systems without having to worry about complex development tools. Such a platform helps in encouraging creativity and enables students to absorb concepts effectively.

LEGO Mindstorms NXT can be used as an instructional tool to bring students into areas that are broad scoped, fun and challenging as well. Students can begin with simple robots and successively proceed to more sophisticated NXT controllers, motors and sensors. Additionally, students can also learn how these components work so that they can attempt to make their own sensors, interfaces, motor drivers and eventually their own robot.

At school level, students are able to develop a deeper and broader understanding of the field of engineering. Consequently, they are able to make a well informed decision when choosing their field of study.

\section{REFERENCES}

[1] http://mindstorms.lego.com/Overview/NXTreme.aspx

[2] http://mindstorms.lego.com/press/2057/Mindstorms\%20Software\%20Announcement.aspx

[3] http://www.lego.com

[4] Kin W. Lau, Heng Kiat Tan, Benjamin T. Erwin, Pave1 Petrovic, Creative Learning in School with LEGO ${ }^{\circledR}$ Programmable Robotics Products, 29th ASEE/IEEE Frontiers in Education Conference, 1999 
[5] Lady Daiana O. Maia, Vandermi J. da Silva, Ricardo E. V. de S. Rosa, Jose P. Queiroz-Neto, Vicente F.de Lucena Jr., An Experience to use Robotics to Improve Computer Science Learning, $39^{\text {th }}$ ASEE/IEEE Frontiers in Education Conference, 2009.

[6] LEGO MINDSTORMS NXT Hardware Developers

[7] LEGO MINDSTORMS NXT Software,

[8] LEGO official website

[9] Tanja Karp, Richard Gale, Laura A. Lowe, Vickie Medina and Eric Beutlich Generation NXT: Building Young Engineers with LEGOs, IEEE Transactions on Education, VOL 53 No. 1, February 2010 . 